\title{
A New Conservative Cold Front? Democrat and Republican Responsiveness to the Passage of the Affordable Care Act
}

\author{
Stephen L. Morgan, Minhyoung Kang
}

Johns Hopkins University

\begin{abstract}
Through an analysis of the 2004 through 2014 General Social Survey (GSS), this article demonstrates that the 2010 passage of the Affordable Care Act (ACA) decreased support for spending on health among Democrats, Independents, and Republicans, contrary to the conjecture that a rigid partisanship equilibrium has taken hold among voters in the United States. Instead, only a partisan deflection is present, with spending preferences declining more for Republicans than for Democrats, and with Independents in between. Through supplemental analysis of the GSS panel data, as well as comparative analysis of other GSS items on national spending preferences, government responsibility, and confidence in leaders, this article also undermines support for an alternative explanation that cannot be entirely eliminated from plausibility, which is that the identified period effect that emerged in 2010 and persisted through 2014 is a response to the Great Recession and resulting deficit spending by the federal government. Implications for public opinion research are discussed, lending support to current models of thermostat effects and policy-specific political mood from the political science literature, which are informed by an older literature on weather fronts in public opinion that originated in the sociology literature.
\end{abstract}

Keywords: political parties; policy support; mood; Affordable Care Act; general social survey

Citation: Morgan, Stephen L., and Minhyoung Kang. 2015. "A New Conservative Cold Front? Democrat and Republican Responsiveness to the Passage of the Affordable Care Act." Sociological Science 2: 502-526.

Received: June 11, 2015

Accepted: July 25, 2015

Published: September 16, 2015

Editor(s): Jesper Sørensen, Delia Baldassarri

DOI: $10.15195 /$ v2.a24

Copyright: (C) 2015 The Author(s). This open-access article has been published under a Creative Commons Attribution License, which allows unrestricted use, distribution and reproduction, in any form, as long as the original author and source have been credited. (C) (i)
$\mathrm{H}$ OW did the 2010 passage of the Affordable Care Act (ACA), commonly referred to as "Obamacare," change health care policy preferences among US residents? If parties and voters are as partisan as is often claimed, then one would expect strongly partisan responses to the passage of the ACA. Republicans should express much greater dissatisfaction with health care policy and favor decreased federal spending on health care. Democrats, in contrast, should rally behind their party, signal support for the recent policy change, and reaffirm their interest in federal spending on health care.

Widely reported telephone polls by media organizations offer results that align well with these expectations. As an illustrative example, consider the CBS News/New York Times telephone poll conducted between April 30, 2015 and May 3, 2015. ${ }^{1}$ Respondents were asked, "From what you've heard or read, do you approve or disapprove of the health care law that was enacted in 2010?" In response, 83 percent of Republicans disapproved of the law in comparison to only 23 percent of Democrats.

Nonetheless, the case for a rigidly partisan reception of the ACA is not settled, even after strong poll differences such as these are recognized. First, approvedisapprove questions, such as the one for the CBS News/New York Times poll above, enable only one type of an analysis of change: approval or disapproval of a 
past event without a baseline prior time point for comparison. Second, the partisan differences revealed by media polls are typically based on responses to questions posed to respondents only after partisanship has been primed. For example, the CBS News/New York Times poll includes the prior questions "Do you approve or disapprove of the way Barack Obama is handling his job as President?," "In general, is your opinion of the Republican Party favorable or not favorable?," and "In general, is your opinion of the Democratic Party favorable or not favorable?" Third, even after such strong priming of party-based differences is introduced, which would surely trigger recall of the positions of political elites from each party, a non-trivial portion of Democrats still expressed disapproval of the ACA. For the CBS News/New York Times poll, nearly 1 in 4 Democrats (23 percent) disapproved of the ACA.

To better interpret widely reported results on the partisan reception of the ACA, we need a survey item that is interpretable before and after passage of the ACA, and preferably one that is elicited without first priming partisanship through prior questions. This article utilizes an item on national spending priorities for health care, from the 2004 through 2014 administrations of the General Social Survey (GSS), which has these desirable properties.

\section{Policy Change and the Preferences of Survey Respondents}

Before introducing the details of measurement and design for our analysis, a brief consideration of the broader literature is helpful to set the stage for an analysis of the response to the passage of the ACA. Accordingly, in this section, we step back from our narrow opening discussion of the response to the ACA in order to consider how changes in the policy preferences of survey respondents have been modeled since the 1970s. We also consider the early usage of the GSS items we will analyze and note how findings from these items have shaped public opinion research on the preferences of survey respondents in both sociology and political science.

\section{Weather and Attitude Change}

In a pioneering study of trends in policy preferences in the United States, the sociologist James A. Davis argued in his 1980 article "Conservative Weather in a Changing Climate" that a conservative "cold front" in the policy preferences of survey respondents had formed, even though the 1970s were properly regarded as a period of substantial liberalization on many social and political attitudes. The support for his claim rested on the analysis of national spending priorities from the 1973 through 1978 administrations of the GSS, and these are the same items we will analyze below for the years 2004 through 2014. Rejecting the relevance of more common oceanic metaphors in public opinion research, Davis (1980:1149) argued:

Perhaps we can do better by leaving the water and taking to the air. Instead of tides and waves, I think we should invoke the well-known distinction between climate and weather... The GSS results suggests this: the long-term liberal (warming?) trend in attitudes and opinions 
continued through the early 1970s, but politicians and practical opinion analysts were wise to wear policy overcoats and mittens since the attitude and opinion weather was dominated by a large-scale conservative cold front.

To further support this conclusion, Davis then demonstrated what he regarded as a surprising lack of group-level variation embedded within the cold front, noting that "the weather of conservatism not only obscured the long-run climatic changes in liberalism, but the sharp change in temperature seems to have hit the various age-education combinations at exactly the same time and with exactly the same strength" (Davis 1980:1152-53).

\section{Thermostats and Mood}

Davis' early piece, crafted after only seven years of GSS data collection, shaped the emergence of a literature now dominated by political scientists, albeit resting prominently on the analysis of more than three decades of subsequent data collection for the GSS. ${ }^{2}$ In their book, The Rational Public: Fifty Years of Trends in Americans' Policy Preferences, Page and Shapiro (1992) first developed a broadly influential "parallel publics" model of opinion change, documenting common trends among groups of survey respondents, with few large policy preference swings for domestic programs, either for groups or in the aggregate. ${ }^{3}$ Two related streams of the political science literature then embraced and developed this argument, still relying to a good extent on the GSS national spending items. First, Wlezien and colleagues proposed a "thermostat" model of opinion change, accepting the position that preferences for spending changes on national priorities vary little across groups but nonetheless do respond in the aggregate to actual policy changes (see Wlezien 1995, 1996, 2004; see also Soroka and Wlezien 2010 and Wlezien and Soroka 2012). Second, Stimson and colleagues developed an argument for the paramount importance of generalized "mood," as part of a theory now labeled macro polity theory. For this model, aggregate preferences for the total size of government expenditure move in countercyclical fashion to national election outcomes, yielding waves of expansion and contraction in spending as alternative parties are ushered into and out of power (see Stimson 2004; see also Erikson, McKuen, and Stimson 2002; Ellis and Stimson 2012; Ura and Ellis 2008).

The role of partisanship in these studies has varied. Page and Shapiro (1992:309) argued that political party identification is one of the only partitions of the population that predicts attitude change across measurable subgroups, writing that "such divergent partisan trends are undoubtedly related to party leadership of public opinion." Yet, both the thermostat and mood models downplay the role of parties, and partisan identity, as they endeavor to demonstrate movement in the strategic center of the electorate that often determines national election outcomes.

At the same time, all strands of this literature have engaged directly with claims that policy decisions reflect the preferences of only some segments of the population (see Bartels 2008, Gilens 2012), perhaps most directly in the edited collection Who Gets Represented? (Enns and Wlezien 2011). And the latest research on mood in political science has considered its contours across alternative policy domains, 
contra Stimson (2004). We will return to this literature when we interpret our results because they lend support to some of its key positions.

\section{Cleavages, Polarization, and Alignment}

While political scientists developed a literature on the direct relationship between policy changes and political preferences elicited by surveys, political sociologists moved away from survey-based public opinion studies in the 1980s and 1990s (see Brooks 2006; Manza and Brooks 2012; Perrin 2014). Still, with work on class cleavages and party positioning, some sociologists remained engaged with election outcomes (see Brooks and Manza 2006, 2007; Manza and Brooks 1999) while others considered trends in attitude polarization and issue alignment by party identification (see DiMaggio, Evans, and Bryson 1996; Baldassarri and Gelman 2008). For these studies, attention to decade-by-decade change has served as an important motivation, even though little attention has been given to year-by-year period effects shaped by specific policy changes. Most recently, increases in inequality and the arrival of the Great Recession have led some sociologists to return to the short-run dynamics of public opinion, electoral outcomes, and policy change (see Brooks and Manza 2013; McCall 2013). Here, the GSS spending items have been analyzed (Manza, Heerwig, and McCabe 2012; McCall and Kenworthy 2009; McCall and Manza 2011), reaching conclusions that agree to only some extent with our conclusions below.

In this article, we focus on attitudes toward health care for two reasons. First, debates over the ACA remain central to ongoing political contestation, five years after passage of the guiding legislation. Second, the timing of the GSS, as well as the specific items available, allow for a more careful analysis of attitudes toward healthcare policy and spending than other policy domains. However, we also pursue reconciliation with recent research that has also analyzed the GSS data in pursuit of explanations for changes between 2008 and 2010 (e.g., Brooks and Manza 2013). This recent research has focused more centrally on the consequences of the Great Recession, aligned with the literature on the rise in partisanship and the rise in social inequality. In contrast to this literature, and after considering other GSS items on alternative spending areas, attitudes toward government responsibility, and confidence in leaders of institutions, we will emphasize an alternative set of conclusions that give greater attention to common directional change.

\section{Data and Methods}

Data are drawn from the 2004 through 2014 General Social Surveys. We first analyze the six cross-sectional samples from 2004 to 2014, all based on the NORC national sample design introduced in 2004 (see Smith, Marsden, and Hout 2015, Appendix A). We then turn to the 2006-2010 panel sample as well as the 2008-2012 panel sample. These panels were initiated as the same cross-sectional samples drawn for the 2006 GSS and the 2008 GSS, respectively, and our panel analysis is based on the subset of respondents who also participated in follow-up waves two and four years later. For this portion of our analysis, we adjust for panel attrition, defined as 
not having participated in all three relevant waves, using complete case weights constructed from estimated logit models.

We handle missing data on outcome measures by using outcome-specific, complete-case weights constructed from underlying logit models for non-response, treating "don't know" responses as missing when constructing these weights. We use imputed political party identification for 95 of the 14,383 cases in the full sample, but our results are only trivially different if we treat these cases as missing, either dropping them from analysis or using weights to adjust for missingness. A more substantial amount of missing data was imputed for predictor variables utilized in one portion of the analysis (e.g., for respondent's education, family income, number of children, and self-reported political ideology). We first estimated chained equations for each variable and then selected the mode from many multiple imputations (because our chosen software, Stata, does not offer a usefully general method for generating single imputations). Additional details of the analysis are provided in the Appendix and in the results below.

\section{Results}

Before presenting our core results, we first offer a timeline of key economic and political events from 2007 through 2010. After these preliminaries, we develop a provisional conclusion, based on an analysis of the 2004 through 2014 cross-sectional samples of the GSS, that support for health spending declined for Democrats, Independents, and Republicans following and in direct response to the passage of the ACA. We then subject this provisional conclusion, which contradicts the expectations of strong partisanship narratives, to a series of supplemental analyses. We use panel data that allows us to assess the strength of the support for the claim that we have identified a meaningful period effect that warrants a causal interpretation. We then consider other items from the GSS, generating support for the position that the effect is not attributable to the Great Recession, nor the ensuing deficit spending of the federal government. Finally, we consider the possibility that the response among Democrats and Republicans is qualitatively different, with Democrats simply indicating that they feel an important social problem has at long last been addressed while, in contrast, Republicans are expressing the position that the government has gone too far. Arguing against this conclusion, and through the analysis of an item typically interpreted as a preference for government-supported health insurance, we show that Democrats also expressed less support in 2010 through 2014 for government responsibility for meeting the costs of health care. Altogether, the results we present in this section develop successively stronger evidence that the provisional conclusion has merit, and furthermore, that there is at least some trace evidence for a broader conservative cold front beyond simply common directional change in response to the passage of the ACA. 


\section{Timeline of Political, Economic, and Legislative Events for the 2008} through 2010 Interval

The most recent six cross-sectional samples of the GSS are positioned three apiece on either side of our focal interval from fall of 2008 through spring of 2010. This interval captures the campaign for healthcare reform and also the resulting passage of the ACA. Yet, as the following timeline makes clear, many other salient events transpired as well, and these other events complicate our analysis.

Timeline of Relevant Events, May 2007 through March 2010

May 2007:

While delivering a speech in Iowa City, Iowa, Barack Obama unveiled a plan for universal health care in the early phase of his campaign for the US Presidency.

September 2007:

While delivering a speech in Des Moines, Iowa, Hilary Clinton unveiled her own plan for universal health care, as momentum built for her campaign for the US Presidency.

December 2007:

The "Great Recession" began. ${ }^{4}$

April 2008:

John McCain, the presumptive Republican nominee for US President, released a rival healthcare plan that did not set universal coverage as a goal but proposed to lower the costs of health care by fostering competition between insurance companies.

July through September 2008:

The mortgage-backed security crisis erupted, and the Federal Reserve, in combination with the Treasury Department, launched unprecedented interventions to stabilize the financial system.

October 2008:

Congress passed and President Bush signed into law the Emergency Economic Stabilization Act of 2008, often referred to as "the bailout."

November 2008:

Barack Obama was elected President while the Federal Reserve and Treasury Department continued to pursue stabilization of the banking system.

January 2009:

President Obama was sworn into office.

February 2009:

Congress passed and President Obama signed into law the American Recovery and Reinvestment Act of 2009, often referred to as "the stimulus." The ARRA ultimately allocated $\$ 840$ billion for domestic spending, following a Keynesian justification for the support of aggregate demand. The largest categories of spending were tax relief for individuals and employees ( $\$ 235$ billion), Medicaid grants to states ( $\$ 93$ billion), education ( $\$ 94$ billion, of which $\$ 51$ billion was composed of grants to states and local school districts to prevent layoffs of 
school employees), transportation (\$39 billion), and infrastructure ( $\$ 34$ billion). President Obama also announced to a joint session of Congress: "So let there be no doubt: Healthcare reform cannot wait, it must not wait, and it will not wait another year."

March 2009:

The White House hosted its first healthcare summit, and Democrats, who controlled both houses of Congress, began to distribute proposed legislation for comment.

June 2009:

The "Great Recession" ended. ${ }^{6}$

July 2009 through March 2010:

A legislative battle was waged over healthcare reform, reaching critical points when: (1) the Democrats lost the super-majority in the Senate with the unexpected death of Senator Kennedy in August 2009; (2) Republican Senator Brown was elected to replace him in January 2010; (3) the Democratic Senate Majority Leader Reid used a reconciliation process in March 2010 to pass the bill without a 60-vote super-majority, which greatly displeased Republican members of Congress.

March 2010:

Congress passed and President Obama signed into law the Patient Protection and Affordable Care Act of 2010.

In hindsight, it is hard to overstate the dramatic nature of the political, economic, and legislative events of this two-year period, in comparison to the two "pretreatment" time periods of 2004 and 2006 and the two "post-treatment" time periods of 2012 and 2014. Still, the GSS was scheduled fortuitously to bracket the 2008 through 2010 interval, and it is especially appropriate for an analysis of the public-opinion response to the passage of the ACA.

Interviews were conducted for the 2008 cross-sectional sample of the GSS from April 17, 2008 through September 13, 2008, with 49\% of interviews completed by the end of May and $89 \%$ of interviews completed by the end of July. Most interviews were therefore concluded before the financial crisis erupted in dramatic enough fashion that many GSS respondents would have taken note of it, and all interviews were concluded before the fall election and the legislative action to address the financial crisis. "High-information" voters who are GSS respondents were likely aware during their 2008 interviews that both of the remaining candidates for the Democratic nomination supported healthcare reform, and perhaps more so than in recent presidential primary races. Actual policy change, however, would have appeared to be a prospect for the future, and not obviously a good bet given the lack of progress on the issue since the 1992 election gave it renewed national prominence, with no ensuing policy changes of note.

Interviews were conducted for the 2010 cross-sectional sample of the GSS from March 15, 2010 through August 12, 2010, with 52\% of interviews completed by the end of April and $87 \%$ of interviews completed by the end of June. Only $4 \%$ of interviews were completed between March 15th and March 21st, the latter date being when Congress passed the ACA. From the 2010 GSS onward, and for the 

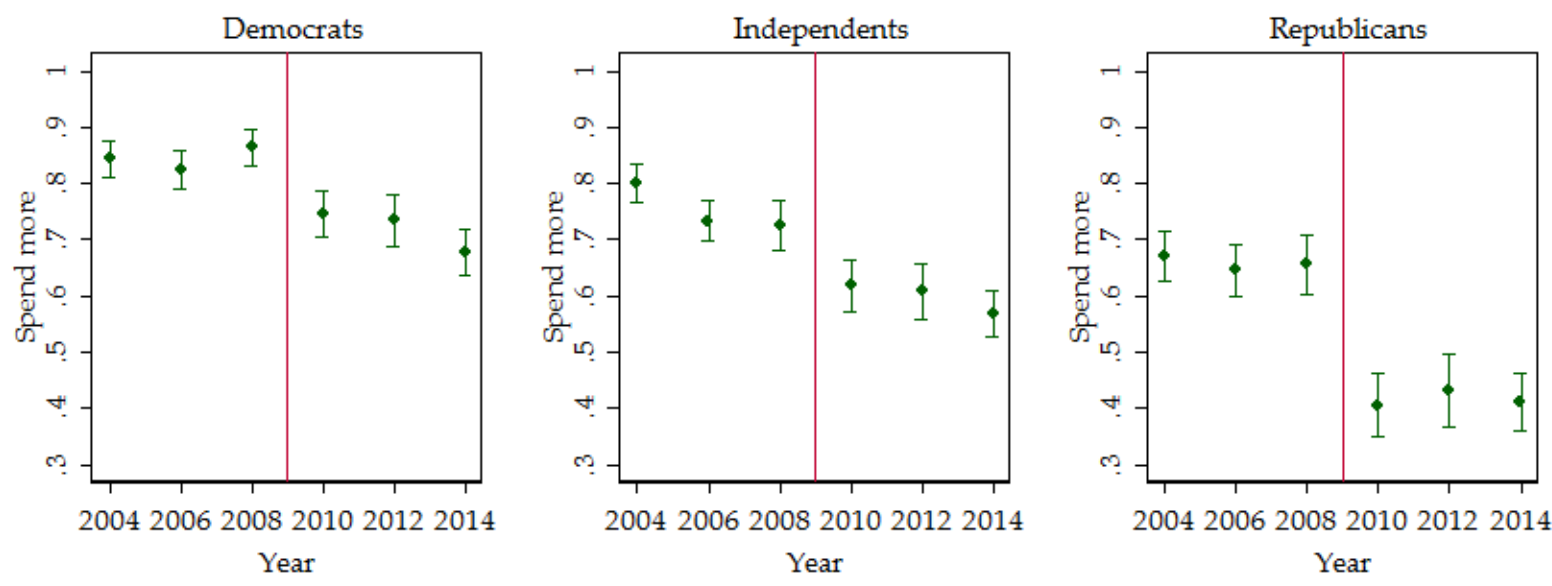

Figure 1: Proportion of respondents, by party identification, who indicate that "too little" money is spent on the nation's health

2012 and 2014 GSS waves, the ACA, usually referred to as "Obamacare," has been a consistent theme in political and media discourse. Even respondents who would not be characterized as high-information voters would likely be aware of at least some of the debate over its passage and implementation.

\section{Passage of the ACA and the Decline in Preferences for Increased Health Spending}

Figure 1 presents the percentage each year of GSS respondents who favored spending more money on the nation's health, separately for Democrats, Independents, and Republicans, with dots for point estimates and error bars for conventional 95 percent confidence intervals. The vertical line between 2008 and 2010 marks the campaign for and eventual passage of the ACA, although as noted above many other events transpired between the 2008 and 2010 interviews as well. Nonetheless, it is clear that for all three groups of respondents, interest in spending money on health declined after the passage of the ACA, even though the decline was largest for Republicans.

Before detailing the pattern of findings, the specific wording of the questionnaire item deserves attention. The GSS has included a national spending battery since 1973, and for nearly all years, including all analyzed in this article, these questions are placed first on the questionnaire. Without contamination from any prior questions, respondents are read the following paragraph (usually in a face-to-face interview):

First I would like to talk with you about some things people think about today. We are faced with many problems in this country, none of which can be solved easily or inexpensively. I'm going to name some of these problems, and for each one I'd like you to tell me whether you think 
we're spending too much money on it, too little money, or about the right amount. ${ }^{7}$

Respondents are then offered a series of spending areas. Since 1984, the particular wording of the first set of spending areas has differed across two survey ballots, determined by randomization. The full details of the two ballots are explained in the Appendix. For now, it is sufficient to note that between 2004 and 2014, approximately half of the respondents, as determined by a random draw, received the item: "Improving and protecting the nation's health." The remaining respondents received the simpler item: "Health."

Our results are based on the analysis of responses to both item wordings, but all estimates that we present are marginal predictions, interpretable as if all respondents received the second terse item wording "Health" rather than "Improving and protecting the nation's health." As such, the results reported in Figure 1 are interpretable as the percentages of GSS respondents who selected the response "too little" when asked their view of spending on "Health." (In fact, there are no substantial wording-difference effects for the health item, but for some of the other items that we will use for comparison below, wording effects are present and must be modeled..$^{8}$ )

Returning to the results presented in Figure 1, between 2004 and 2008 support for health spending was very strong among Democrats, with between 82 and 86 percent of Democrats responding that too little money was being spent. For Independents and Republicans, support for health spending was lower than for Democrats in these pre-ACA years. Nonetheless, between 2004 and 2008, approximately twothirds of both Independents and Republicans also supported increased spending on health.

From 2010 onward, the pattern of change is clear, and it is similar in direction for all three groups. Most dramatically, for Republicans the decline between 2008 and 2010 in responding "too little" was 25.0 percent (standard error, 4.0), and the decline between the average of 2004 through 2008 and the average of 2010 through 2014 was 24.1 percent (standard error, 2.2). For Democrats, the corresponding declines were 11.8 percent (standard error, 2.7) and 12.4 percent (standard error, 1.6), and for Independents they were 10.7 percent (standard error, 3.3) and 15.5 percent (standard error, 1.8).

Before relating these patterns to the extant literature, we should first explain why they are not a consequence of our decision on how to categorize GSS respondents as Democrats, Independents, and Republicans. Table 1 presents self-reported party identification, tabulated for each GSS cross-sectional sample from 2004 through 2014, using two different coding rules. ${ }^{9}$ After dozens of prior questions, GSS respondents were asked in each year: "Generally speaking, do you usually think of yourself as a Republican, Democrat, Independent, or what?" If respondents selected something other than Republican, Democrat, or Independent, they are coded as "Other."10 If respondents selected Independent, they were then asked, "Do you think of yourself as closer to the Republican or Democratic Party?"11 The first panel of Table 1 presents yearly distributions based on an inclusive categorization of Independents, ignoring their follow-up responses. The second panel of Table 1 provides alternative yearly distributions based on a narrow categorization of Independents that reassigns 
Table 1: Percentage Self-identified Political Party by Year, 2004-2014 Cross-Sectional Samples of the GSS

\begin{tabular}{|c|c|c|c|c|c|}
\hline Year & Democrat & Independent & Republican & Other & Weighted $N$ \\
\hline \multicolumn{6}{|c|}{ Inclusive categorization of Independents, including "leaners" } \\
\hline 2004 & 34.1 & 35.1 & 29.8 & 1.1 & 2,811 \\
\hline 2006 & 30.9 & 40.1 & 27.3 & 1.7 & 2,999 \\
\hline 2008 & 36.3 & 35.7 & 26.2 & 1.8 & 2,022 \\
\hline 2010 & 32.1 & 42.6 & 22.7 & 2.7 & 2,043 \\
\hline 2012 & 33.4 & 41.0 & 23.4 & 2.2 & 1,974 \\
\hline 2014 & 31.2 & 44.8 & 21.7 & 2.3 & 2,536 \\
\hline \multicolumn{6}{|c|}{ Narrow categorization of Independents, excluding “leaners" } \\
\hline 2004 & 44.0 & 16.1 & 38.8 & 1.1 & 2,811 \\
\hline 2006 & 42.2 & 21.7 & 34.5 & 1.7 & 2,999 \\
\hline 2008 & 48.4 & 15.6 & 34.2 & 1.8 & 2,022 \\
\hline 2010 & 45.6 & 19.0 & 32.7 & 2.7 & 2,043 \\
\hline 2012 & 46.0 & 20.4 & 31.4 & 2.2 & 1,974 \\
\hline 2014 & 44.6 & 21.1 & 31.9 & 2.3 & 2,536 \\
\hline
\end{tabular}

Notes: Total $N$ is 14,383 . Data are weighted by the non-response weight distributed with the GSS, WTSSNR. 95 cases were imputed from an underlying multinomial model. Appendix Table A1 presents the same cross-tabulation without these imputed cases to demonstrate that the consequences are trivial when less than one percent of cases are imputed.

leaning Independents as either Democrats or Republicans (and thereby leaving the Independent category with only stout Independents who indicate "neither" in response to the follow-up question).

The results presented above in Figure 1 are based on the first categorization. What would happen to the pattern in Figure 1 for health care spending if we allowed Independents who lean to be categorized as Democrats and Republicans? As we show in the Appendix (see Figure A1 and Table A2a), the decline for Democrats is slightly larger while the decline for Republicans is slightly smaller. This is a general pattern that holds for all subsequent results. The results we present in the main body of the article show larger partisan differences, relative to a parallel analysis offered in the Appendix.

Table 1, however, reveals two other points of interest. First, the percentage of GSS respondents who identified as Republican declined between 2004 and 2014, by either 7 or 8 percent, depending on the categorization. Over the same time period, the percentage of those who identified as Other increased slightly. These changes may reflect greater willingness to self-identify with movements critical of the Republican party, such as the Tea Party movement. If so, the results for the Republican party that we present below may be more moderate than would otherwise be the case.

Second, the increase in the proportion of GSS respondents who identified as Democrats peaked in 2008 (at 36 percent in the first categorization and 48 percent in the second), and this inflection point is best interpreted as a leading indicator that 
the Democrats would take Congress and the Presidency in the fall 2008 election, which occurred after the GSS interviews were completed that year. The subsequent decline in 2010 is present for both categorizations, but the decline is larger for the first categorization that counts Independents who lean toward the Democratic party as Independents. Had the changes we observe in party identification for 2010 through 2014 not occurred, the conclusions we offer in the main body of this article would likely be even stronger (i.e., if it were the case that, contrary to fact, Democrats and Republicans retained some of those who changed party identification to Independent or Other from 2010 through 2014).

Now, to return to the substantive results on the response to the ACA, the abrupt decline in support for health spending is consistent with the recent literature on thermostat effects that has shown how policy changes are reflected in subsequent preferences for changes in spending (see Soroka and Wlezien 2011). But, the presence of the decline for Democrats as well as Independents and Republicans is also consistent with the early position of Davis (1980) that conservative cold fronts can emerge in liberalizing climates, even though this decline is for a single spending area and provides no evidence of a broader cold front. The larger relative decline among Republicans is consistent with some of the new literature on partisanship, even though the decline among Democrats is inconsistent with its strongest variants.

Our provisional conclusion is that a conservative cold front may have arrived in 2010, fueled by the passage of the ACA, and persisted through 2014. The remainder of the results we present below will torture this provisional conclusion, all in the service of convincing the reader that it has substantial merit. To do so, we must provide evidence that the effects observed for health spending are genuine, and also that the cold front is broader than just the decline observed for this single GSS item.

\section{Are the declines interpretable as causal effects?}

We offer two types of analysis as our first support for the claim that the abrupt declines depicted in Figure 1 are genuine causal effects. For Figure 2, we offer an equivalent set of results for the 2004 through 2014 GSS cross-sections, but now we adjust for differences in the backgrounds of respondents. For Figure 2, we include additional characteristics of respondents in each year to assess whether trends in personal characteristics, such as possible declines in income from the onset of the Great Recession, may be associated with the abrupt decline in support for health spending. This adjustment also protects against contamination from compositional change in categories of party identification. In particular, we include in the underlying models adjustment variables for gender, age (seven dummies for eight age cohorts), education (in years), family income (in log form, recoded to midpoints of categories adjusted for inflation and with Pareto imputation of the top category), race-ethnicity (three dummies for four categories), whether born in the US, whether any children under the age of 18 are in the home, and number of children. We also include two dummies for industry of employment in order to capture particularistic interests in spending, where the two dummies are for the health industry and the education industry (in comparison to an implicit 

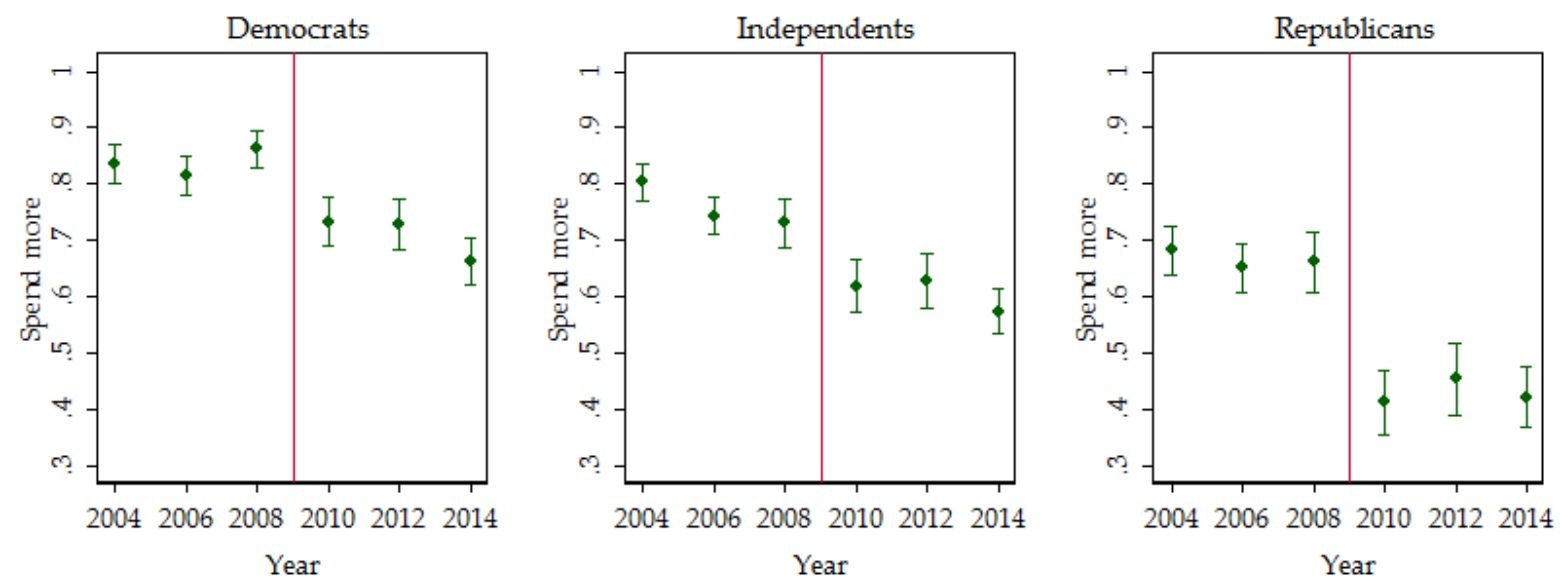

Figure 2: Background-adjusted proportion of respondents, by party identification, who indicate that "too little" money is spent on the nation's health

reference category of all others, which includes respondents without an industry of employment because they are unemployed or not in the labor force).

These additional predictors help to account for a substantial portion of the variation in responses within each year, but Figure 2 shows that the estimates of the period effect from 2010 through 2014 are largely unchanged. Moreover, the average differences between Democrats, Independents, and Republicans change very modestly.

For Figure 3, we present results from analogous models but now adjust also for self-reported political ideology. Later in the GSS interview, respondents are asked:

We hear a lot of talk these days about liberals and conservatives. I'm going to show you a seven-point scale on which the political views that people might hold are arranged from extremely liberal - point 1 - to extremely conservative - point 7 . Where would you place yourself on this scale?

For the models underlying Figure 3, we include six dummy variables for the seven points on the ideology scale (in addition to the adjustment variables utilized for the models summarized by Figure 2). As a result of how self-reported ideology predicts support for spending, the predicted differences between Democrats, Independents, and Republicans are reduced somewhat. However, the basic pattern of results over time is unchanged.

Taken together, Figures 2 and 3 provide evidence against explanations centered on compositional change in background and expressed political ideology after the interval in which the ACA was passed. Still, it is possible, as with all observational research, that we have not included in our cross-sectional adjustments some crucial characteristics of individuals that changed between 2008 and 2010 and that, if measured, would cast doubt on our claim that the declines for 2010 through 2014 

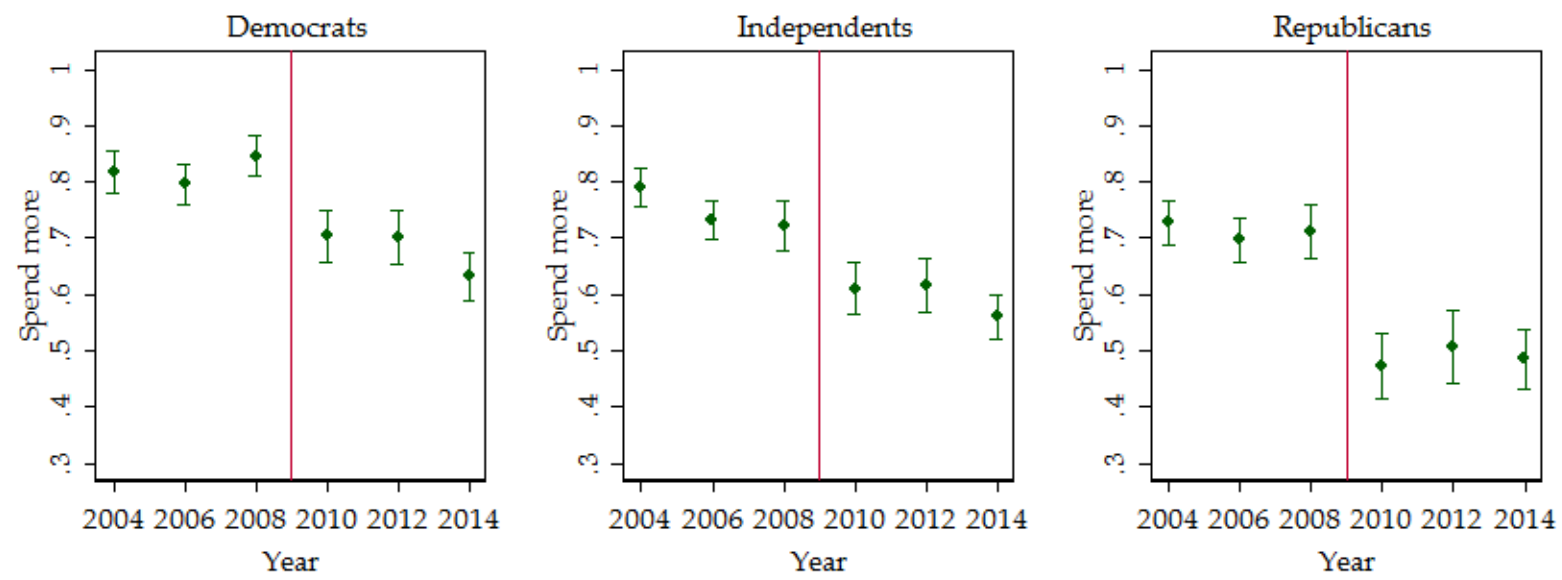

Figure 3: Background and ideology-adjusted proportion of respondents, by party identification, who indicate that "too little" money is spent on the nation's health

are causal in nature. Our project is like all others: we cannot prove the nonexistence of unobserved confounders.

Fortunately, the GSS permits another type of analysis that, we think, should greatly reduce the concern of a fair critic. We can observe responses to the same question for two groups of respondents before and after the passage of the ACA. The 2006 cross-sectional sample was re-interviewed in both 2008 and 2010 while the 2008 cross-sectional sample was re-interviewed in both 2010 and 2012.

Figure 4 presents predicted percentages in favor of increased health spending, analogous to those reported earlier in Figure 1, but now estimated for the GSS respondents who entered the sample in 2006 and who were re-interviewed in both 2008 and 2010. ${ }^{12}$ A similar abrupt decline is present between 2008 and 2010, providing support for our provisional conclusion that the observed declines are genuine causal effects.

The point estimates have larger standard errors, which reflects larger sampling error because the effective sample size is smaller when limited to those 2006 respondents who were re-interviewed in both 2008 and 2010. The declines in support for health spending were again largest for Republicans, at 21.6 percent (standard error, 4.8), but the declines for Democrats were large as well, at 16.8 percent (standard error, 4.2 percent). In this case, the declines for Independents were more modest, at 9.9 percent (standard error, 4.2). We should also note that we do not allow individuals to change party identification for our classification of their 2008 and 2010 responses. Thus, for example, any 2006 Independents who subsequently identified as Democrats or Republicans in 2008 or 2010 are still classified for all three years in Figure 4 as Independents.

Figure 5 offers results of the same form but for GSS respondents who entered the sample in 2008 and who were re-interviewed in both 2010 and 2012. The decline in support of increased health spending between 2008 and 2010 is again present, with declines of 10.3, 9.8, and 17.8 percent for Democrats, Independents, 

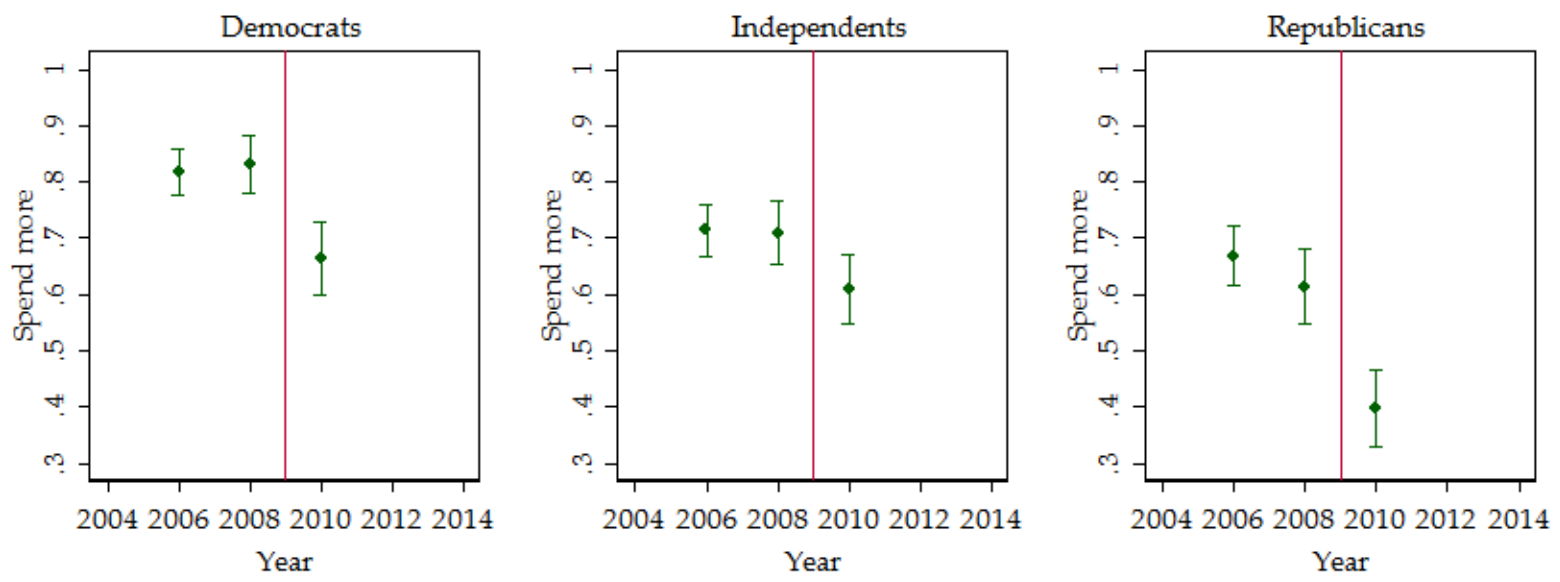

Figure 4: Proportion of respondents, by party identification, who indicate that "too little" money is spent on the nation's health, for the 2006 Cross-sectional Sample, Re-interviewed in 2008 and 2010
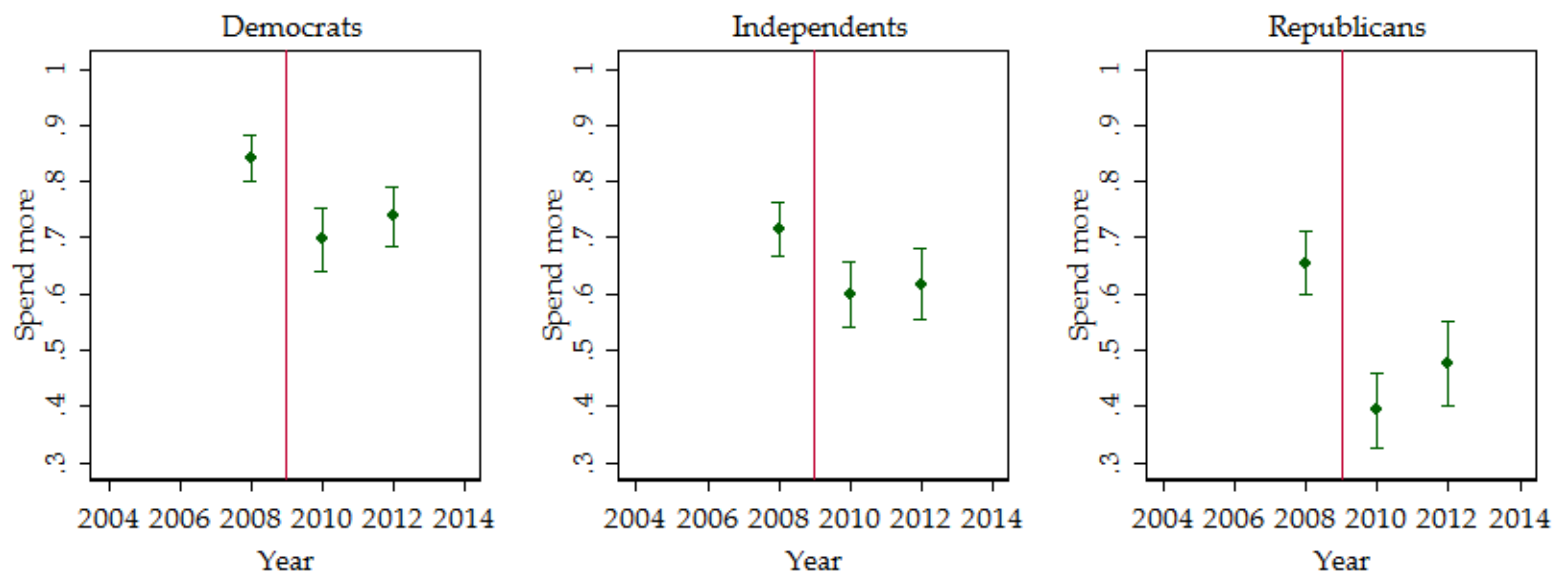

Figure 5: Proportion of respondents, by party identification, who indicate that "too little" money is spent on the nation's health, for the 2008 Cross-sectional Sample, Re-interviewed in 2010 and 2012

and Republicans, respectively (standard errors of 3.4, 4.1, and 4.7). For each group, an increase in support for spending is present in 2012 in comparison to 2010, but not enough to reverse the decline observed between 2008 and 2010 (and not enough that we can rule out expected sampling variation). ${ }^{13}$

Altogether, the results presented in Figures 2 through 5 support our provisional conclusion that the passage of the ACA caused an abrupt and genuine decline in support for health spending. The decline in support is present for Democrats, Independents, and Republicans, and it is very unlikely to reflect compositional change among those who identify with one political party or another. Most directly, the decline can be observed for the same respondents before and after the passage of the ACA. 
Table 2: Changes between 2004-2008 and 2010-2014 in the Percentage of Respondents who Indicate that "Too Little" Money is Spent on All GSS Spending Areas

\begin{tabular}{lcccccc}
\hline & \multicolumn{2}{c}{ Democrats } & \multicolumn{2}{c}{ Independents } & \multicolumn{2}{c}{ Republicans } \\
& Change & Std. Err. & Change & Std. Err. & Change & Std. Err. \\
\hline Space exploration & 4.5 & 1.5 & 7.0 & 1.5 & 10.8 & 1.9 \\
The environment & -7.2 & 1.7 & -4.1 & 1.8 & -11.2 & 2.3 \\
Health & -12.4 & 1.6 & -15.5 & 1.8 & -24.1 & 2.2 \\
Assistance to big cities & -4.8 & 1.8 & -3.4 & 1.5 & 0.8 & 1.4 \\
Law enforcement & -7.2 & 2.0 & -5.2 & 1.9 & -4.3 & 2.3 \\
Drug rehabilitation & -4.8 & 2.0 & -3.4 & 1.9 & 1.6 & 2.3 \\
Education & -0.8 & 1.3 & -1.9 & 1.6 & 0.8 & 2.0 \\
Assistance to Blacks & -3.9 & 2.1 & -1.4 & 1.7 & -0.6 & 1.6 \\
National defense & -3.3 & 1.6 & $<0.1$ & 1.6 & 2.4 & 2.3 \\
Assistance to other countries & -6.0 & 1.3 & -3.4 & 1.2 & -0.9 & 0.8 \\
Assistance for the poor & -6.7 & 1.5 & -6.5 & 1.8 & -4.7 & 2.6 \\
Highways and bridges & 7.9 & 1.7 & 2.9 & 1.6 & 12.6 & 2.0 \\
Social security & -8.5 & 1.6 & -8.9 & 1.6 & -5.0 & 2.1 \\
Mass transportation & 2.3 & 1.7 & -2.1 & 1.6 & -7.6 & 2.0 \\
Parks and recreation & -1.5 & 1.7 & 1.7 & 1.5 & -1.0 & 1.8 \\
Assistance for childcare & -4.2 & 1.7 & -7.4 & 1.6 & -6.7 & 2.0 \\
Supporting scientific research & -1.2 & 1.9 & -1.1 & 1.7 & -0.9 & 2.1 \\
\hline
\end{tabular}

\section{Are the declines the effects of the ACA or instead the Great Reces- sion and emergent distaste for deficit spending?}

In the literature on causal inference, our analysis of the abrupt decline in support for health spending between 2008 and 2010 in Figures 2 through 5 would be labeled an analysis of the effects of a cause. But, in this case, the cause is a time interval, which is nothing but a nominal marker for an underlying true cause that is not identified directly in our analysis. Moreover, events other than the passage of the ACA also occurred between 2008 and 2010 and could have generated the declines we have observed. The obvious candidates are (1) the economic crisis now labeled the Great Recession in the literature and (2) distaste for the growth of deficit spending that was in part a fiscal response to the Great Recession itself.

Fortunately, the GSS, as detailed above, asks respondents about other spending areas beyond health. If either the recession or stimulus spending were responsible for the decline in support for health spending, then we would expect to see declines in support for spending in other areas as well, with declines largest in areas where stimulus funds were committed. Table 2 presents changes between the average of 2004 through 2008 and the average of 2010 through 2014 in each of the spending areas polled (and listed in the order presented to respondents). ${ }^{14}$

To dispense with one interesting possibility, consider first the item for support of spending on scientific research, presented in the bottom row. Here, we have little to no change for all three groups, with the declines in the point estimates well within 
the expected range that could be attributable to sampling error alone. In view of this lack of change, it seems unlikely that the decline in support for "health" spending reflects an interpretation of the item by respondents that gives much weight to scientific medical research, spending for which did increase slightly following the stimulus legislation. Accordingly, the observed decline remains consistent with our interpretation that it is a response to the ACA, and, furthermore, that it is a forward looking response shaped by beliefs that health spending would increase because of federal appropriations beyond the transitory stimulus funding. ${ }^{15}$

For other spending areas, where stimulus spending was substantial, such as education, we have no substantial change. Where we do see change, it is sometimes in areas where some have argued that not enough stimulus money was committed, such as for "Highways and bridges," and "Space exploration." In other cases, it is clearly in the direction of a conservative cold front, such as for "The environment," "Assistance to Blacks," "Assistance for the poor," "Social security," and even "Assistance for childcare." Still, the consistent declines for these spending areas are much smaller than the decline in support for health spending. And, important for the cold front possibility, it cannot be stressed enough that these declines are present for both Democrats and Independents, and in many cases were larger for them (although declines off of higher initial levels, making comparisons with Republicans complicated). Finally, for a few areas we see partisanship of note when considering the direction of change, such as for "National defense," "Assistance to other countries," and "Mass transportation," with Democrats favoring decreased spending on the first two and Republicans favoring decreased spending on the last.

Other interpretations of the overall pattern of Table 2 are possible, but our interpretation is that attitudes toward spending on health are distinctively negative. What this overall menu of changes suggests is aptly labeled a confirmatory extension. Support for spending fell, even among Democrats, for many areas traditionally favored by left-leaning parties. But, the change was not uniform; some areas in which spending did increase at the federal level as part of the stimulus effort, such as education, showed no substantial change in either direction. And, where under-investment may be agreed upon by all, such as for highways and bridges, we see increased support for spending among all groups.

The patterns revealed in Table 2, therefore, do not support the alternative explanation that changes in support for health spending are just one response embedded within a more general desire to restrain the deficit spending of the federal government that opened up in response to the Great Recession. The overall pattern of change is more in line with the cold front narrative than strong forms of partisan response, primarily because the direction of change is mostly the same for all three groups, and it is not limited to health spending alone. This last possibility, however, raises an interesting question: How well does the GSS reveal partisanship? The answer, we show below, is quite well. Before we present those results, we next consider one last way to investigate change in support for health spending. 


\section{Are Democrats simply satisfied voters, unlike Republicans?}

We have claimed so far that our provisional conclusion is consistent with a stream of literature that tracks variation in the mood of voters and that the overall pattern may even support the position that a conservative cold front has formed, fueled by the passage of the ACA. One important counterclaim must be considered: While the decline for Republicans may indicate opposition to the ACA, the decline for Democrats may represent the increasing prevalence of the belief that an important need has at long last been addressed, and no further increase in spending is necessary any longer. Although it is not possible to determine from any direct measures on the GSS whether this explanation has merit, some relevant analysis is possible.

The national spending items on the GSS are approached by respondents with comparatively little context, given that they are the first questions asked of them during their interviews. Only after several dozen attitude and information questions are respondents prompted to select a party identification in response to: "Generally speaking, do you usually think of yourself as a Republican, Democrat, Independent, or what?" Then, they are asked the political ideology question explained above for the analysis reported in Figure 3.

At this point in the GSS interview, one must assume, in line with the literature on context effects in survey response (e.g., Schwarz and Sudman 1992; Tourangeau, Rips, and Rasinski 2000), that respondents are primed for recall of the positions most commonly aligned with their party identification and political ideology. In this primed state, they are then asked four questions on the responsibility of government. They are asked to place themselves along a handcard scale that shows five points, with one pole indicating full individual responsibility and the other pole indicating full government responsibility. The specific wordings of these items are presented in the Appendix. Table 3 presents changes between the average of 2004 through 2008 and the average of 2010 through 2014 for each of the four government responsibility items, listed in the order presented to respondents.

First, consider the third row of Table 3, which reports the change in the percentage of respondents, before and after passage of the ACA, who agree that it is the responsibility of the government in Washington to help individuals pay for doctors and hospital bills. ${ }^{16}$ This item is often considered to measure direct support for government health insurance, which is how the ACA is often interpreted. In Table 3, a decline in support for this government responsibility is present for all three groups, although a larger relative decline is present for Republicans than Democrats and Independents (14.1 percent in comparison to 5.1 and 7.7 percent, respectively).

Yet, it is the absolute decline for Democrats that is important. If Democrats favored lower spending on health in 2010 through 2014 because they felt that the ACA had met a need, we would either expect no change on government responsibility toward health care or even a more positive response on government responsibility (either as expressive defense of the ACA in particular, or at least generalized support for a bold policy position staked out by their party). Instead, we see a decline in 2010 through 2014.

It is important to note that these attitudes are issued by respondents only after partisan identity has been strongly primed by a series of immediately prior ques- 
Table 3: Changes between 2004-2008 and 2010-2014 in Attitudes Toward the Responsibility of the Government in Washington

\begin{tabular}{lcccccc}
\hline & \multicolumn{2}{c}{ Democrats } & \multicolumn{2}{c}{ Independents } & \multicolumn{2}{c}{ Republicans } \\
& Change & Std. Er. & Change & Std. Err. & Change & Std. Err. \\
\hline $\begin{array}{l}\text { Should do everything possible to im- } \\
\text { prove the standard of living of all poor }\end{array}$ & -0.5 & 2.2 & -3.6 & 2.0 & -0.9 & 1.7 \\
$\begin{array}{l}\text { Americans? } \\
\text { Should do more to solve the country's }\end{array}$ & 1.0 & 2.2 & -3.6 & 1.9 & -5.5 & 1.8 \\
$\begin{array}{l}\text { problems? } \\
\text { Should help in paying for doctors and }\end{array}$ & -5.1 & 2.2 & -7.7 & 2.1 & -14.1 & 2.3 \\
hospital bills? & & & & & & \\
\\
$\begin{array}{l}\text { Should help improve the living stan- } \\
\text { dards of Blacks / African-Americans? }\end{array}$ & 2.5 & 1.9 & 0.3 & 1.6 & -0.3 & 1.3 \\
\hline
\end{tabular}

tions, unlike the spending items considered above. Even with such priming, fewer Democrats supported government responsibility for healthcare costs following the passage of the ACA. ${ }^{17}$ In other words, it is possible, perhaps even likely, that if political party and ideology had not been primed as they were, an even larger decline in attitudes toward government responsibility for healthcare costs would have been observed.

Now, consider the remaining government responsibility items presented in Table 3. The differences suggest that Independents favored diminished government responsibility for two of the three other items, and Republicans for (at least) one. In all cases, however, the changes over time were not as large as for government responsibility for health costs, matching the basic pattern of results for Table 2 for these two groups. The support of Democrats for other types of government responsibility held steady, relative to expected sampling error. Thus, for these items, we see no generalized support for a broader cold front beyond the health domain, although this may reflect the presence of a context effect strong enough to eliminate the conservative drift in spending support revealed above in Table 2 for Democrats.

\section{Is something wrong with the GSS?}

With so much common directional change in time, a fair critic might wonder whether the GSS data are simply not up to the task of revealing the important partisan differences so frequently detailed in scholarship and media reporting. To allay such concerns, we conclude our empirical analysis with a consideration of another widely used battery of items from the GSS. Between 2004 and 2014, a randomly determined two thirds of GSS respondents were read the following statement: 
Table 4: Changes between 2004-2008 and 2010-2014 in the Percentage of Respondents with Confidence in Leaders of Institutions

\begin{tabular}{lcccccc}
\hline & \multicolumn{2}{c}{ Democrats } & \multicolumn{2}{c}{ Independents } & \multicolumn{2}{c}{ Republicans } \\
& Change & Std. Err. & Change & Std. Err. & Change & Std. Err. \\
\hline Major companies & -2.5 & 1.6 & -0.3 & 1.6 & 0.3 & 2.2 \\
Organized religion & -2.0 & 1.8 & -1.7 & 1.6 & -4.1 & 2.3 \\
Education & 1.6 & 2.1 & -1.5 & 1.9 & -9.6 & 2.2 \\
Executive branch of the federal gov. & 13.3 & 1.7 & 0.3 & 1.4 & -23.1 & 1.9 \\
Organized labor & 1.2 & 1.7 & -0.4 & 1.5 & -3.4 & 1.5 \\
Press & 1.1 & 1.5 & -0.9 & 1.2 & -0.3 & 1.0 \\
Medicine & 3.6 & 2.2 & 1.0 & 2.0 & -2.4 & 2.5 \\
TV & 1.2 & 1.5 & 1.4 & 1.3 & 2.1 & 1.3 \\
U.S. Supreme Court & 1.8 & 2.0 & -5.9 & 2.0 & -9.0 & 2.4 \\
Scientific community & 2.3 & 2.3 & -0.7 & 2.1 & -2.9 & 2.6 \\
Congress & -2.9 & 1.6 & -3.2 & 1.3 & -9.4 & 1.5 \\
Military & 5.8 & 2.2 & 3.0 & 2.1 & -3.7 & 2.4 \\
Banks and financial institutions & -11.6 & 1.7 & -11.3 & 1.7 & -18.2 & 2.1 \\
\hline
\end{tabular}

I am going to name some institutions in this country. As far as the people running these institutions are concerned, would you say that you have a great deal of confidence, only some confidence, or hardly any confidence at all in them?

Table 4 presents results based on the items presented after this statement is read, coding for changes in the percentage of respondents selecting "a great deal of confidence."

In Table 4, expected partisanship is present in the differences between the average of 2004 through 2008 responses and the average of 2010 through 2014 responses. Confidence in the executive branch of the federal government increased substantially for Democrats, decreased substantially for Republicans, and was unchanged for Independents, continuing a well documented trend in these items since the 1970s (see Smith 2012). More generally, when we see change in Table 4, it is frequently in the opposite direction for Democrats and Republicans, with Independents in between. The areas of greatest across-party agreement would appear to be for the leaders of organized religion, TV, Congress, and, especially, the leaders of banks and financial institutions. Overall, then, we see quite substantial partisanship in the GSS data when questions are targeted at political leaders, and this is also clear in the spending items when one considers average levels rather than direction of change, as in Figures 1 through 5.

\section{Conclusions}

Through an analysis of the 2004-2014 GSS data, we have made the case that the 2010 passage of the ACA decreased support for spending on health among Democrats, 
Independents, and Republicans, contrary to the conjecture that a rigid partisanship equilibrium has taken hold among voters in the United States. Instead, only a partisan deflection is present, with spending preferences declining more for Republicans than for Democrats, and with Independents in between.

Many other areas of social spending associated with left-leaning parties also lost some support after the 2010 passage of the ACA, although not all and none to the extent that we observed for health spending. To the extent that common directional change exists in these additional areas of social spending, we have interpreted them as constituting a cold front, fueled initially and abruptly as a response to the ACA. Accordingly, we see weak spillover to other areas, even as we are clear that this is an interpretation that we have placed on these trends, and other readers may not see the results as we do.

As Davis (1980) demonstrated, conservative cold fronts can emerge during liberalizing climates. Since the 1970s, and probably for at least 20 years prior (see Davis 2012, Marsden 2012, Stouffer 1955), a warming trend in social attitudes has been driven by both cohort replacement and change over the lifecourse. When conservative cold fronts arise, typically they do not do so because these classic cohort and age effects reverse, but rather because period effects emerge to counter them. For spending on the nation's health, our interpretation is that the source of change appears to be the campaign for and passage of the ACA. Accordingly, we reach a different conclusion than Brooks and Manza (2013; see pages 738-40) who argue that there is essentially no support for a government overreach narrative in recent mass opinion polls. With the benefit of additional years of GSS data that were unavailable to them, as well as an alternative sets of models based on different design choices, we see considerable evidence within the GSS responses for precisely this scenario.

But, of course, even if one accepts our weather interpretation, we cannot provide any direct evidence of a linkage between the passage of the ACA and other spending areas. Nor can we distinguish between a "large-scale conservative cold front" like the one Davis detected in the 1970s or instead a spotty and fast-moving clipper system, after which a warming high-pressure system will arrive. The latter would appear more plausible given the sizes of the changes in policy domains other than health care, but we have no direct evidence to provide a clear interpretation or to develop an informed forecast.

Although we think it is very difficult to argue against the position that a period effect emerged in 2010 that has persisted through 2014, its source may not align with our interpretation. A fair critic could argue that the GSS reveals a general distaste for federal spending, as an elaboration of common aversion to heightened deficit spending. We have argued against this interpretation, noting how an analysis of all areas of spending polled for the GSS does not reveal a general displeasure with spending. Moreover, increased support for spending is present in some areas that received substantial stimulus funding (education) and other areas that likely did not receive as much spending as respondents desired (highways and bridges).

It is also possible that this emergent 2010 period effect represents declining approval of the Obama presidency, independent of particular policy changes, but here the explanation does not align sufficiently with direct measures of confidence 
in the leadership of the executive branch of the federal government. Although we showed that confidence did indeed decline precipitously for Republicans in 2010 through 2014 relative to 2004 through 2008, the change for Democrats is strongly positive and is close to zero for Independents. It is conceivable that a complex pattern of individual level heterogeneity could lend support to this counter explanation, but it appears to us as rather unlikely.

\section{Discussion}

These results have implications for alternative traditions of analysis in public opinion research. The literature on partisanship may too strongly argue that policy change is interpreted in partisan fashion. Without contesting the position that elected officials are partisan, and likely to listen disproportionately to members of their constituencies who are most able to support their candidacies with available economic resources, our results suggest that policy preferences among voters and survey respondents can be less partisan and more uniform when attention is focused on direction of change.

At the same time, arguments that lump all policy domains together in aggregate scales of "mood" are quite likely unreasonably reductive, especially over time frames when policy change is substantial and not uniform. This position is consistent with the very latest literature on mood, which recommends greater disaggregation by policy domain than the foundational literature on mood would suggest, as in an ongoing project on the relationship between policy activity in legislatures and targeted mood (see http://www.policyagendas.org/moodapp, accessed June 3, 2015). Generalized mood responses may exist, and if so our results suggest that they are triggered by narrower policy changes.

For sociology, it is puzzling that, as Brooks, Manza, Perrin, and others have observed, survey-based public opinion research is very much out of fashion in our journals. This valuation of the survey mode of investigation for political processes may change, however, because of the complexity shown in studies such as this one, which follows on other recent related work of others (e.g., Brooks and Manza 2013, McCall 2013). We now have period effects of emergent interest, set against age and cohort effects, which are amenable to interpretation. And the GSS panel, at least for the 2006 through 2012 interval, enables identification of them.

\section{Notes}

1 Poll results were drawn from http://www . cbsnews. com/news/poll-views-on-economy -isis-more-negative (accessed July 6, 2015), but they are available through the usual online archives (see CBS News/New York Times 2015). Prior administrations of similar CBS News/New York Times polls with substantially similar questions show very similar results for aggregate disapproval of the ACA, suggesting that the results presented in the main text broken down by party are unlikely to represent an emergent pattern. 
2 Davis (1992), however, extends the climate-weather metaphor, tracking the movement of opinions through 1989, and noting the emergence of a liberal cooling climate in the 1980s. Neither piece by Davis became a citation classic in contrast to the political science literature that absorbed it.

3 Page and Shapiro (1982) presages the 1992 argument, using Davis to support the claim of aggregate "changes in a conservative direction" (pg., 30). Page and Shapiro (1982) is also one of the very few political science pieces to cite Davis (1980).

4 The recession was not dated as having begun until a year later when the Business Cycle Committee of the National Bureau of Economic Research (NBER) released a report on December 1, 2008. To be precise, the peak of the expansionary period that preceded the recession was dated as December 2007, and lagging indicators of the recession only became clear over the course of 2008.

5 The Secretary of the Treasury was authorized to spend $\$ 700$ billion to stabilize the financial system. As of May 2015, according to the journalism non-profit ProPublica, $\$ 615$ billion was spent, and $\$ 670$ billion was returned, for a net profit to the US treasury of $\$ 55$ billion (http: //projects . propublica.org/bailout, accessed on May 15, 2015).

6 The recession was not dated as having ended until a September 10, 2010 report was released by the Business Cycle Committee of NBER.

7 In addition to the response categories offered in the statement, the interviewer has a "don't know" response category to utilize. In this article, we treat "don't know" responses as a type of non-response, equivalent to cases where respondents do not provide an answer when presented with the spending area. Trends in "don't know" responses appear to us to represent trendless fluctuation, but additional work on "opinionation" for this item may be worthwhile.

8 See Rasinski (1989) and Smith (2006) for analyses of the general pattern of item-wording effects since 1984, which were very small for the health item in their analyses as well.

9 The total sample size across all six cross-sectional samples is 14,383, and the weighted N's for each GSS cross-sectional sample in the final column are rounded (and hence do not add up to this number). The sizes of the cross-sectional samples differ by year because of the GSS budget and year-to-year variation in design, along with slight variation in levels of survey non-response.

10 Because the size of the "Other" group is small, we do not report results for it throughout this article (because sampling error generates too much imprecision). These respondents are, however, included in most underlying models, and results are available for them. Point estimates for their responses typically align most closely with Republicans.

11 If respondents selected Democrat or Republican, they were then asked to indicate whether they were a "strong" or "not very strong" Republican or Democrat. We ignore this distinction in our results.

12 These models are adjusted for panel attrition, using a complete case weighting strategy where the weights were constructed from an underlying logit model with predictor variables similar to those used for the models summarized by Figure 2. Panel attrition, with respect to observed characteristics, appears to be weakly patterned, and as such the adjustment has almost no impact on the results.

13 We should also note that the models underneath Figures 4 and 5 do not adjust for any individual differences. If we adjust for baseline background and political ideology in 2006 and 2008, respectively, as we did for Figures 2 and 3, we can eliminate some of the between-party differences, but we do not alter the declines observed after 2008 at all. It is possible that we could explain some change if we allowed background and political 
views to change, by introducing new measurements from the re-interviews. We do not do so because any such change in the estimates could reflect a form of over-control bias. It is sufficient for our purposes to simply show that the same individuals, on average, decreased their support for health spending.

14 As with the health spending results, the differences reported in Table 2 are based on marginal predictions that are interpretable as if all respondents received the item wordings listed in Table 2, even though a randomized half actually received the alternative wordings. See above and the Appendix for details.

15 It bears noting that the response followed closely on the heels of the passage of the ACA, not in response to actual spending. One counter-narrative would suggest that the decline is actually a response to the stimulus funds that were used to fortify Medicaid. Given the consistency of response between 2010 and 2014, this seems unlikely.

16 We coded agreement as selecting either "I strongly agree it is the responsibility of the government to help" or "I agree it is the responsibility of the government to help." We coded the other three response options ("I agree with both answers," "I agree that people should take care of themselves," and "I strongly agree that people should take care of themselves") as non-agreement with government responsibility.

17 In the Appendix, we offer Table A3b, which reports the type of results in Table 3 restricted only to the immediate before and after cross-sections in 2008 and 2010. This alternative table shows that the decline is also present and even stronger for Democrats relative to other groups (at a decline of 7.7 percent, relative to 4.7 percent for Independents and 11.4 percent for Republicans). However, the standard errors, given the reduction in samples sizes for the comparison parameters, are approximately 70 percent larger.

\section{References}

Baldassarri, Delia and Andrew Gelman. 2008. "Partisans without Constraint: Political Polarization and Trends in American Public Opinion." American Journal of Sociology 114:408-46. http://dx.doi.org/10.1086/590649.

Bartels, Larry M. 2008. Unequal Democracy: The Political Economy of the New Gilded Age. New York: Russell Sage.

Brooks, Clem. 2006. "Voters, Satisficing, and Policymaking: Recent Directions in the Study of Electoral Politics." Annual Review of Sociology 32:191-211. http://dx. doi .org/10.1146/ annurev.soc.32.061604.123142.

Brooks, Clem and Jeff Manza. 2006. "Social Policy Responsiveness in Developed Democracies." American Sociological Review 71:474-94. http://dx.doi.org/10.1177/ 000312240607100306.

- 2007. Why Welfare States Persist: The Importance of Public Opinion in Democracies. Chicago: University of Chicago Press.

-. 2013. "A Broken Public? Americans' Responses to the Great Recession." American Sociological Review 78:727-48. http://dx.doi.org/10.1177/0003122413498255.

CBS News/New York Times. 2015. CBS News/New York Times Poll, Apr 2015, USCBSNYT.050515A, CBS News/New York Times [producer]. Storrs, CT: Roper Center for Public Opinion Research [distributor].

Davis, James A. 1980. “Conservative Weather in a Liberalizing Climate: Change in Selected NORC General Social Survey Items, 1972-78." Social Forces 58:1129-56. http://dx. doi. org/10.1093/sf/58.4.112. 
—. 1992. "Changeable Weather in a Cooling Climate Atop the Liberal Plateau: Conversion and Replacement in Forty-Two General Social Survey Items, 1972-1989." The Public Opinion Quarterly 56:261-306. http://dx.doi .org/10.1086/269322.

—. 2012. "On the Seemingly Relentless Progress in Americans' Support for Free Expresssion, 1972-2006." Pp. 19-37 in Social Trends in American Life: Findings from the General Social Survey Since 1972, edited by P. V. Marsden. Princeton: Princeton University Press.

DiMaggio, Paul, John Evans, and Bethany Bryson. 1996. “Have American's Social Attitudes Become More Polarized?" American Journal of Sociology 102:690-755. http: //dx. doi .org/ 10.1086/230995.

Ellis, Christopher and James A. Stimson. 2012. Ideology in America. New York: Cambridge University Press. http://dx.doi.org/10.1017/CB09781139094009.

Enns, Peter and Christopher Wlezien, Eds. 2011. Who Gets Represented? New York: Russell Sage Foundation.

Erikson, Robert S., Michael MacKuen, and James A. Stimson. 2002. The Macro Polity. New York: Cambridge University Press.

Gilens, Martin. 2012. Affluence and Influence: Economic Inequality and Political Power in America. Princeton: Princeton University Press.

Manza, Jeff and Clem Brooks. 1999. Social Cleavages and Political Change: Voter Alignments and Us Party Coalitions. New York: Oxford University Press.

—. 2012. "How Sociology Lost Public Opinion: A Genealogy of a Missing Concept in the Study of the Political." Sociological Theory 30:89-113. http://dx.doi .org/10.1177/ 0735275112448054.

Manza, Jeff, Jennifer A. Heerwig, and Brian J. McCabe. 2012. "Public Opinion in the "Age of Regan": Political Trends, 1972-2006." Pp. 117-45 in Social Trends in American Life: Findings from the General Social Survey Since 1972, edited by P. V. Marsden. Princeton: Princeton University Press.

Marsden, Peter V., Ed. 2012. Social Trends in American Life: Findings from the General Social Survey Since 1972. Princeton: Princeton University Press. http://dx . doi .org/10.1515/ 9781400845569.

McCall, Leslie. 2013. The Undeserving Rich: American Beliefs About Inequality, Opportunity, and Redistribution. Cambridge: Cambridge University Press.

McCall, Leslie and Lane Kenworthy. 2009. “Americans' Social Policy Preferences in the Era of Rising Inequality." Perspectives on Politics 7:459-84. http://dx . doi .org/10.1017/ S1537592709990818.

McCall, Leslie and Jeff Manza. 2011. “Class Differences in Social and Political Attitudes in the United States." Pp. 552-70 in The Oxford Handbook of American Public Opinion and the Medias, edited by R. Y. Shapiro and L. R. Jacobs. Oxford: Oxford University Press. http://dx.doi.org/10.1093/oxfordhb/9780199545636.003.0034.

Page, Benjamin I. and Robert Y. Shapiro. 1982. "Changes in Americans' Policy Preferences, 1935-1979." The Public Opinion Quarterly 46:24-42. http: //dx . doi .org/10 . 1086/268697.

- 1992. The Rational Public: Fifty Years of Trends in Americans' Policy Preferences. Chicago: University of Chicago Press.

Perrin, Andrew J. 2014. American Democracy: From Tocqueville to Town Halls to Twitter. Cambridge: Polity.

Rasinski, Kenneth A. 1989. "The Effect of Question Wording on Public Support for Government Spending." Public Opinion Quarterly 53:388-94. http://dx .doi .org/10.1086/ 269158. 
Schwarz, Norbert and Seymour Sudman, Eds. 1992. Context Effects in Social and Psychological Research. New York: Springer-Verlag. http://dx.doi.org/10.1007/ 978-1-4612-2848-6.

Smith, Tom W. 2006. "Wording Effects on the National Spending Priority Items across Time, 1984-2004." GSS Methodological Report No. 107, National Opinion Research Center, Chicago, Illinois.

—. 2012. "Trends in Confidence in Institutions, 1973-2006." Pp. 177-211 in Social Trends in American Life: Findings from the General Social Survey Since 1972, edited by P. V. Marsden. Princeton: Princeton University Press.

Smith, Tom W., Peter V. Marsden, and Michael Hout. 2015. General Social Surveys, 1972-2014, Cumulative Codebook. Chicago: National Opinion Research Center.

Soroka, Stuart Neil and Christopher Wlezien. 2010. Degrees of Democracy: Politics, Public Opinion, and Policy. New York: Cambridge University Press.

Stimson, James A. 2004. Tides of Consent: How Public Opinion Shapes American Politics. New York: Cambridge University Press. http://dx.doi .org/10.1017/CB09780511791024.

Stouffer, Samuel A. 1955. Communism, Conformity, and Civil Liberties: A Cross-Section of the Nation Speaks Its Mind. Garden City: Doubleday.

Tourangeau, Roger, Lance J. Rips, and Kenneth A. Rasinski. 2000. The Psychology of Survey Response. New York: Cambridge University Press.

Ura, Joseph Daniel and Christopher R. Ellis. 2008. "Income, Preferences, and the Dynamics of Policy Responsiveness." PS: Political Science \& Politics 41:785-94. http: //dx. doi .org/ 10.1017/S104909650808102X.

Wlezien, Christopher. 1995. "The Public as Thermostat: Dynamics of Preferences for Spending." American Journal of Political Science 39:981-1000. http://dx.doi.org/10.2307/ 2111666.

-. 1996. "Dynamics of Representation: The Case of Us Spending on Defence." British Journal of Political Science 26:81-103. http://dx. doi .org/10.1017/S0007123400007420.

-. 2004. "Patterns of Representation: Dynamics of Public Preferences and Policy." Journal of Politics 66:1-24. http://dx.doi.org/10.1046/j.1468-2508.2004.00139.x.

Wlezien, Christopher and Stuart N. Soroka. 2011. “Inequality in Policy Responsiveness?" Pp. 285-310 in Who Gets Represented?, edited by P. Enns and C. Wlezien. New York: Russell Sage Foundation.

Acknowledgements: A prior version of this paper was presented at Princeton University in March 2015, and comments from seminar participants are gratefully acknowledged. We thank Peter Enns and Michael Hout for comments on the first complete draft in May 2015 , and we thank the reviewer and editorial staff for their suggestions in response to our original submission in June 2015.

Stephen L. Morgan: Department of Sociology, Johns Hopkins University. E-mail: stephen.morgan@jhu.edu.

Minhyoung Kang: Department of Sociology, Johns Hopkins University. E-mail: mkang25@jhu.edu. 